\title{
Bilinguals in a monolingual and a bilingual speech mode: The effect on lexical access
}

\author{
CARLOS SOARES and FRANCOOIS GROSJEAN \\ Northeastern University, Boston, Massachusetts
}

\begin{abstract}
The time course of lexical access in fluent Portuguese-English bilinguals and in Englishspeaking monolinguals was examined during the on-line processing of spoken sentences using the phoneme-triggered lexical decision task (Blank, 1980). The bilinguals were tested in two distinct speech modes: a monolingual, English or Portuguese, speech mode, and a bilingual, codeswitching, speech mode. Although the bilingual's lexical decision response times to word targets in the monolingual speech modes were identical to those of the monolingual subjects, their response times to code-switched word targets in the bilingual mode were significantly slower. In addition, the bilinguals took longer to detect nonwords in both the monolingual and bilingual modes. These results confirm that bilinguals cannot totally deactivate their other language when in a monolingual speech mode. It is hypothesized that bilinguals search both lexicons when confronted with nonwords, even when in a totally monolingual mode, and that they search the base-language lexicon before the other lexicon when in a bilingual, code-switching, speech mode.
\end{abstract}

A number of factors have been found to affect lexical access (or word recognition) during the on-line processing of speech in monolinguals. These factors include word frequency, word length, frequency of the first syllable, and the accompanying syntactic and semantic context (Blank, 1980; Foss, 1969; Foss \& Blank, 1980; Grosjean, 1980; Marslen-Wilson \& Welsh, 1978; Mehler, Segui, \& Carey, 1978; Rubenstein \& Pollack, 1963). Furthermore, various models have attempted to describe the process of lexical access during the on-line processing of speech (Foss \& Blank, 1980; Marslen-Wilson \& Welsh, 1978; Morton, 1969; Cole \& Jakimik, 1979), whereas others have proposed accounts of the organization of the internal lexicon (Bradley, 1977; Forster, 1976).

Much less is known about lexical organization and access in the bilingual, that is, the person who uses two languages on a regular basis. Most studies related to this topic have concentrated on whether bilinguals have

This research was based in part on the first author's doctoral dissertation. We wish to thank Keith Kluender, Harlan Lane, Joanne Miller, and Michael Terman for their comments on earlier drafts of this manuscript, and Steve Harkins for assistance with statistical analyses. We are grateful to Joanne Miller for the use of her laboratory facilities, supported by NIH-NINCDS Grant NS 14394. This research was further supported in part by Department of Health and Human Services Biomedical Research Support Grant RR 07143 and NIH Grant NS 14923. Very special thanks go to Michael McCloskey, Charles Clifton, and an anonymous reviewer for their very helpful comments and suggestions concerning revisions to the first draft of the paper. Requests for reprints should be sent to: Carlos Soares, Marketing Education, M.S. ID, Data General Corporation, 2400 Computer Drive, Westboro, MA 01580. one or two lexicons, and the results of these studies are almost evenly split in favor of either the one- or the twolexicon position. This dichotomy is probably due to a confounding of the basic question with the tasks used to examine it (Grosjean, 1982; Kolers \& Gonzalez, 1980; Paradis, 1978). Some tasks, such as the shortterm recall of word lists, may force subjects to attend to the form and language of words, thereby yielding a twolexicon result, whereas other tasks, such as categoryinstance judgments or long-term recall of word lists, yield results consistent with the one-lexicon hypothesis (Caramazza \& Brones, 1979; Kolers, 1963, 1966a, 1968; Taylor, 1971; Tulving \& Colotla, 1970). In order to account for these divergent results, Paradis (1978, $1980 \mathrm{a}, 1981)$ has proposed a model in which the bilingual has two lexicons, one for each language. These language lexicons are in turn differentially connected to a conceptual store that contains the bilingual's languagefree experiences, concepts, and mental representationsin short, what is known about the world.

In the present study, we investigate how bilinguals access their two language lexicons during word recognition as a function of the speech mode they are in. We assume that in their everyday lives bilinguals find themselves at various points along a situational continuum that induces a particular speech mode (Grosjean, 1982). At one end of the continuum, bilinguals are in a totally monolingual speech mode in that they are speaking to monolinguals of language $A$ or $B$. At the other end of the continuum, bilinguals find themselves in a bilingual speech mode in that they are speaking to bilinguals with whom they normally mix languages. For the purposes of the present study, we refer to the two 
ends of the continuum, but it should be kept in mind that these are end points and that intermediate speech modes do exist.

In the monolingual speech mode, bilinguals adopt the language of the monolingual interlocutor. They also deactivate, as well as they can, the other language. This deactivation has led to much theorizing and controversy around the notion of a language switch or a monitoring system (Macnamara, 1967; Obler \& Albert, 1978; Paradis, 1980b). What is certain, however, is that bilinguals rarely deactivate the other language totally. Evidence for this has been found in cross-language Stroop tests (Obler \& Albert, 1978; Preston \& Lambert, 1969), word-nonword judgments (Altenberg \& Cairns, 1983), and comprehension tasks using the phoneme monitoring paradigm (Blair \& Harris, 1981). One of the aims of the present study is to investigate further the residual activation of one language when the bilingual is processing the other language in a monolingual speech mode.

In the bilingual speech mode, the bilingual chooses a base language and brings in elements of the other language. One way of doing this is to code-switch, that is, to shift completely to the other language for a word, a phrase, a clause, or a sentence. For example:

Eu quero depositar isto no meu checking account
(I want to deposit this in my checking account).

Va chercher Marc and bribe him avec un chocolat chaud with cream on top

(Go get Marc and bribe him with a hot chocolate with cream on top).

In the first example, the base language is Portuguese and the switch (italicized) is in English; in the second example, the base language is French and the switches are in English. Code-switching is a domain that is now receiving increasing attention: Sociolinguists are studying the factors that lead to code-switching (see, e.g., Gumperz, 1970, Scotton \& Ury, 1977, and Vaid, 1980), and linguists are examining the constraints that govern code-switching and whether there is a code-switching grammar (e.g., Lipski, 1978; Pfaff, 1979; Poplack, 1980; Woolford, 1983).

Little is known about the on-line processing of codeswitched clauses and phrases or the lexical access of codeswitched words. The literature most closely related to this question dates back a number of years and represents investigations into the perception and production of ungrammatical language mixtures, not code-switches. For example, Kolers (1966b) haphazardly mixed English and French passages and found that bilinguals read them more slowly than they did monolingual passages. Macnamara and Kushnir (1971) asked bilinguals to judge the truth value of sentences in which French and English words were randomly mixed and found that the reaction times to these sentences were slower than reaction times to monolingual sentences. But these and other studies have been criticized on at least two counts: The language mixtures were ungrammatical in that they violated both monolingual rules and code-switching restraints (no bilingual would ever have uttered them), and the bilingual subjects were never put in a bilingual speech mode (the experimenters and the experimental settings were usually monolingual). Since then, a number of studies (Neufeld, 1973; Pandi, 1975; Wakefield, Bradley, Yom, \& Doughtie, 1975) have controlled these factors, at least in part.

In the present study, we used a phoneme-triggered lexical decision task (PTLD; Blank, 1980) to investigate lexical access in the bilinguals' two speech modes. In the monolingual speech mode, we compared PortugueseEnglish bilinguals with English monolinguals and examined the residual activation of the bilinguals' other language. Because our bilingual subjects were highly fluent in their two languages, we did not expect them to differ from monolinguals when confronted with a word (as opposed to a nonword) in the base language. However, in line with results obtained by other researchers using visual rather than auditory stimuli (Altenberg \& Cairns, 1983; Diamond, 1982), we did expect longer reaction times to nonwords.

In the bilingual speech mode, we investigated the time it took to decide whether a code-switched stimulus is a word or a nonword. In this case, our expectations were less clear-cut. On the one hand, we made sure that our bilingual subjects were indeed in a bilingual, codeswitching speech mode, and this was expected to facilitate the recognition of code-switched words. We could therefore expect no difference between the time it took to recognize a base-language word in a monolingual speech mode and a code-switched word in a bilingual speech mode. However, we could also reason that accessing code-switched words would take more time because these words would not be in the base language and the bilingual listener would use a strategy of always accessing the base-language lexicon before running through the other lexicon. In addition, such factors as the acousticphonetic configuration of the code-switched words, the attitudes bilinguals have toward code-switching, and the number of code-switches prior to the stimulus item might affect recognition times. Hence, we had no a priori predictions concerning the time it would take to access code-switched words, although the frequency with which code-switching occurs among bilinguals suggested that the differences, if any, between baselanguage lexical access and code-switching lexical access would be minimal.

\section{METHOD}

\section{Subjects}

Thirty-six right-handed males participated in this study. Eighteen of the subjects were English-speaking monolinguals, 20-24 years old (mean $=21.3$ years). The other 18 subjects were Portuguese-English bilinguals whose first language was Portuguese and who first came into contact with English after 12 years of age. Their ages ranged from 20 to 35 years (mean $=$ 
24.2 years). The bilinguals were selected for approximately equal and high fluency in Portuguese and English. Fluency was assessed by: a questionnaire in which the bilinguals rated their fluency in reading, writing, speaking, and understanding Portuguese and English; a reading test in which they were timed while reading aloud passages of equal length in Portuguese and English; and a naming task in which, in $1 \mathrm{~min}$, the bilinguals named objects found in various settings. In order to participate in the study, the bilinguals had to rate their overall fluency in Portuguese and English equally, read the passages in approximately the same amount of time $( \pm 10 \%)$, and name approximately the same number of objects in both languages $( \pm 15 \%)$. In addition, care was taken to ensure that the bilinguals used both languages on a regular basis. All of the bilinguals had moved to the United States in their adolescence and, therefore, had learned English in school and through their interactions with English-speaking friends and the community in general.

\section{Materials}

A first group of 66 sentences was constructed in English. These sentences were then translated into Portuguese to make up a second group of sentences. Care was taken that the targetbearing words and nonwords in the Portuguese and in the English versions of the sentences started with similar stop consonants and occurred in approximately the same place in the sentence. A third group of 66 code-switched sentences was then constructed. This was done by replacing the target word or nonword, as well as other nouns, in the Portuguese sentences with the appropriate English word or nonword from the English sentence. Therefore, in any one code-switched sentence, there were several code-switches so that when listening to those sentences the subjects would not simply respond to the first English word. In addition, sentences were generated such that the code-switched versions would provide a context in which code-switching would be likely to occur. An example of the English, Portuguese, and code-switched versions of one of the target-word sentences is provided below (italicized words indicate the target words; capitalized words indicate code-switched words).

English: After lunch, the children asked for a piece of cake for dessert.

Portuguese: Depois do almoço os miudos pediram uma fatia de bolo para sobremesa.

Code-switched: Depois do LUNCH os miudos pediram uma fatia de $C A K E$ para DESSERT.

Of the 66 sentences in each language group (English, Portuguese, and code-switched), 24 contained target words, 24 contained target nonwords, and the rest were fillers. In order to ensure that the subjects attended to the meaning of the sentences, 21 of the 66 sentences in each set were followed by a question. The English target words were of medium to high frequency (range 13 to 274 , with a mean of 86 ), according to the analysis by Kučera and Francis (1967). The Portuguese target words, which were translations of the English, were assumed to be of approximately equal frequency, although a frequency count of Portuguese words was not available. The nonwords in English and Portuguese were constructed by changing some of the phonemes of real words and were possible words. All three language versions of the 66 sentences were recorded by a female speaker fluent in Portuguese and English. A tone was then placed on the second track of the tape such that its onset coincided with the burst of the target phoneme. The tone, which was inaudible to the subjects, started a timer on a PDP-11/10 computer. The time was stopped when the subjects pressed one of two buttons labeled "word" and "nonword."

\section{Procedure}

All subjects were tested individually. The stimulus material was presented binaurally over headphones (Telephonics TDH-39P) by a Revox B77 tape recorder. All subjects used the index and middle fingers of the right hand to press the "word" and "nonword" buttons. For half of the subjects, the labels "word" and "nonword" were reversed.

Each subject was given a sheet of paper, on which appeared, in the left margin, a list of the target phonemes for which they were to listen and, in the right margin, a series of spaces in which to answer questions. In order to avoid indicating the language of the stimulus word in the bilingual speech mode, this orthographic presentation of the list of target phonemes was chosen over the auditory presentation used by Blank (1980). From this point on, the procedure followed that described by Blank (1980). The subject listened for a word (or nonword) in a sentence that began with a prespecified phoneme. Once this word (or nonword) had been found, the subject had to indicate as quickly as possible whether or not it was a real word. Some sentences were followed by questions to which the subject was asked to respond.

After having been given the instructions, the subjects were presented 5 practice sentences (at least 1 of each type), 2 of which were followed by questions. For the monolinguals, the 66 experimental sentences were divided into three sets of 22 sentences. The monolingual subjects were divided into three groups of six, and each group was presented one of the sets. Hence, the monolingual, English-speaking subjects heard only 22 sentences. The bilingual subjects, on the other hand, heard all 66 sentences. Of these, one set of 22 was from the English group of sentences, a second set of 22 was from the Portuguese group, and a third set was from the code-switched group. Each set contained different sentences. To induce each of the two monolingual speech modes (English and Portuguese), the subjects were given oral instructions in the appropriate language and were presented 5 practice sentences in that language. As for the bilingual speech mode, the subjects were given oral instructions in Portuguese mixed with English code-switches; they were also asked to read aloud a Portuguese passage containing code-switches and were given 5 practice sentences from the code-switching group. The bilinguals were divided into three groups of six, each group being assigned a particular sequence of sets of sentences according to a partial Latin square design.

\section{RESULTS AND DISCUSSION}

Since the subgroups of bilingual subjects in the different speech modes were exposed to different sentences, the reaction times for words and nonwords were averaged for individual subjects. This set of individual mean reaction times was then used for all of the analyses discussed below.

\section{Lexical Access in the Monolingual Speech Modes}

Figure 1 presents the mean word-nonword reaction times for the English-speaking monolinguals and for the Portuguese-English bilinguals in the English-language speech mode. We first note that the bilinguals' lexical decision times for English words are very similar to those of the monolinguals: 849 and $868 \mathrm{msec}$, respectively. ${ }^{1}$ We also note that the nonword reaction times for the bilinguals are substantially slower than those for the monolinguals: 1,625 and $1,301 \mathrm{msec}$, respectively.

A $2 \times 2$ analysis of variance confirmed these obser- 


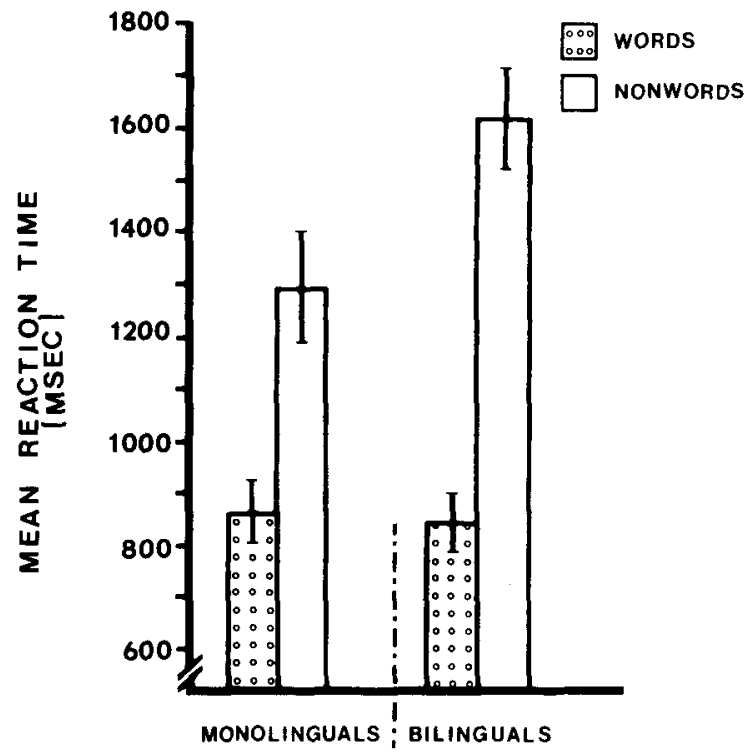

Figure 1. Mean reaction times to English words and nonwords for English-speaking monolinguals and for PortugueseEnglish bilinguals in an English monolingual speech mode. Bars indicate \pm 1 standard error.

vations. First a word main effect $[\mathrm{F}(1,34)=125.33$, $\mathrm{p}<.001]$ was obtained, confirming that words were responded to significantly faster than nonwords ( 859 and $1,463 \mathrm{msec}$, respectively), as is typically found in lexical decision tasks (e.g., Blank, 1980). Second, the group main effect was not significant $[F(1,34)=2.03$, $\mathrm{p}<.15$ ] indicating that although the overall mean reaction time for the monolinguals $(1,085 \mathrm{msec})$ was faster than that for the bilinguals $(1,237 \mathrm{msec})$, there was substantial overlap in their distributions. Third, a significant group $\mathrm{x}$ word interaction was obtained $[F(1,34)=10.19, p<.01]$. A Tukey HSD post hoc analysis (Kirk, 1968) of this interaction revealed that although the reaction times to words for monolinguals and bilinguals were not significantly different, the bilinguals were significantly slower than the monolinguals in responding to nonwords $(\mathrm{p}<.05)$.

In addition, we compared the bilinguals' responses to words and nonwords in their English and Portuguese monolingual speech modes. We found no difference in the lexical decision times for English and Portuguese words [849 and $836 \mathrm{msec}$, respectively; $\mathrm{t}(17)=.33$, n.s.] or for English and Portuguese nonwords [1,623 and $1,536 \mathrm{msec}$, respectively; $t(17)=1.01$, n.s.] , indicating that our bilinguals were equally fluent in their two languages.

Two main points emerge from this analysis. The first is that fluent bilinguals in a monolingual speech mode can access words just as rapidly as can monolinguals. The second, and more interesting, point is that bilinguals in a monolingual speech mode are substantially slower than monolinguals at responding to nonwords. This second finding replicates the results obtained by other researchers using a lexical decision task in the visual domain (Altenberg \& Cairns, 1983; Diamond, 1982 ) and provides evidence for the residual activation of the language not being processed when the bilingual is in a particular speech mode. A possible explanation of this lexical decision effect is that, in the case of words, only one lexicon is searched-that of the base language being spoken. However, when a nonword is presented, a complete search of the first lexicon is immediately followed by a (partial?) search of the other lexicon, before the stimulus is classified as a nonword. What is surprising is that such a search should be taking place at all in the auditory modality. Here one could reason that the acoustic-phonetic cues of the nonword should be strong enough to indicate that only the base language is being spoken. And yet, as in the visual modality, a search of the other lexicon seems to be taking place.

A number of predictions follow from this dualsearch hypothesis. The first is that the greater the acoustic-phonetic difference between the two languages, the smaller the difference between monolinguals and bilinguals on nonword decisions. In the case of English and Portuguese, the acoustic-phonetic difference is not as great as that between other potential language pairs, and, hence, one obtains a significant effect. A second prediction is that nonwords that violate the phonotactic rules of the other language (even though the two languages are quite similar phonetically) should be reacted to more quickly than stimuli that do not violate these rules. The violation of phonotactic rules should either prevent or shorten the search of the other lexicon. And a third prediction is that nonword reaction times should be longer in a trilingual, in that he or she has three lexicons to search instead of only two. But this triple search will of course interact with a number of factors, such as the acoustic-phonetic characteristics of the three languages, the trilingual's fluency in these languages, his or her daily use of these languages, and so on.

\section{Lexical Access of Code-Switches in the Bilingual Speech Mode}

The mean reactions for the bilinguals in the two monolingual speech modes (English, Portuguese) and in the bilingual speech mode are presented in Figure 2. We note first of all that reaction times to code-switched words $(1,001 \mathrm{msec})$ are slower than those to words in either of the monolingual speech modes (English = $849 \mathrm{msec} ;$ Portuguese $=836 \mathrm{msec}$ ). Second, we observe that nonwords are reacted to in a similar manner in all speech modes (English $=1,623 \mathrm{msec}$; Portuguese = $1,536 \mathrm{msec}$; code-switched $=1,645 \mathrm{msec}$ ). A series of analyses of variance confirmed these observations. First, a 2 (word, nonword) $\times 3$ (English, Portuguese, codeswitched) analysis of variance revealed significant word $[F(1,17)=121.22, p<.001]$ and speech mode $[F(2,34)$ $=3.48, \mathrm{p}<.05]$ main effects. Again, the word main effect indicates that reaction times to words $(895 \mathrm{msec})$ were significantly faster than those to nonwords $(1,602 \mathrm{msec})$, as is typically found in lexical decision 


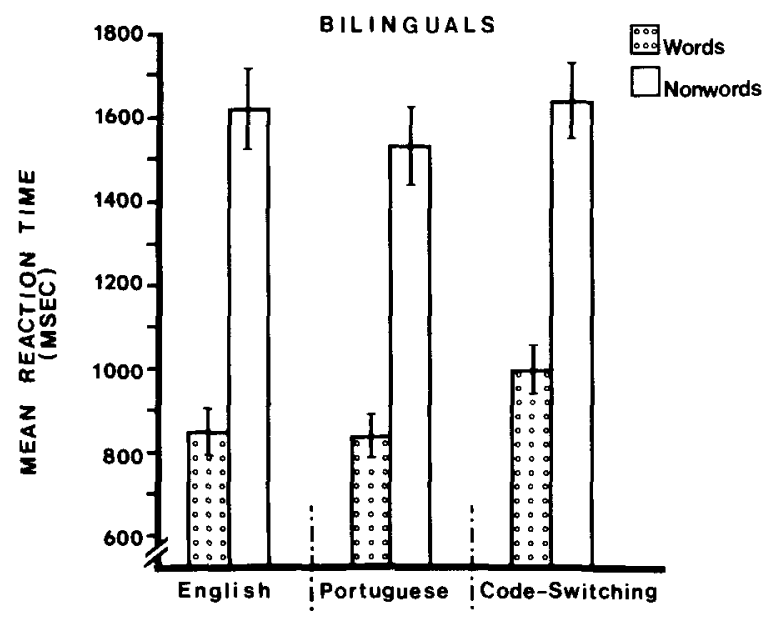

Figure 2. Mean reaction times to words and nonwords for bilinguals in the English and Portuguese monolingual speech modes and in the bilingual, code-switching speech mode. Bars indicate \pm 1 standard error.

tasks. The Tukey HSD post hoc analysis (Kirk, 1968) of the speech mode main effect showed that overall reaction times (words and nonwords) in the code-switched condition were significantly slower than those in the monolingual language modes (English $=1,236 \mathrm{msec}$; Portuguese $=1,186 \mathrm{msec} ;$ code-switched $=1,322 \mathrm{msec}$; $\mathrm{p}<.05$ ). The word $\mathrm{x}$ speech mode interaction failed to reach significance, probably due to the nonwords. However, separate analyses of variance of the wordnonword variable demonstrated not only that reaction times to words were significantly slower in the bilingual code-switching mode $[\mathrm{F}(2,34)=8.48, \mathrm{p}<.001]$, but also that reaction times to nonwords in the different speech modes were not significantly different $[F(2,34)$ $=1.03$, n.s.]. In sum, bilinguals took longer to access code-switched words in the bilingual speech mode than they did base-language words in the monolingual speech modes, and the time they took to react to nonwords was identical across all modes.

To account for these findings, we will make two assumptions. The first is that bilinguals always search both lexicons whenever confronted with a nonword, even in a bilingual speech mode, and the second is that whatever the task and the speech mode, bilinguals always search the base-language lexicon first. The first assumption explains the similar reaction times to nonwords in both the monolingual and the bilingual speech modes. Irrespective of the mode, a nonword triggers a dual search. The second assumption explains the difference in reaction times to base-language words in the monolingual speech modes and to code-switched words in the bilingual speech mode. When a subject listens to words in the monolingual speech mode, a search of the base-language lexicon results in lexical access times that are similar to those obtained by monolinguals. However, in a bilingual speech mode, the base-language strategy will cause a delay in the access of code-switched words. These words belong to the other lexicon and are therefore accessed only after the base lexicon has been searched, and hence the delay in reaction times.

Of course, this delay (like that of the nonwords) can be affected by a number of factors. For example, we found a nonsignificant correlation of -0.45 between the density of code-switches before the target word and the time it took to access the code-switched word. This could mean that if a bilingual is in an environment in which the frequency of code-switching is quite high, he or she will expect code-switches and hence will speed up the search of the other lexicon (e.g., by keeping it "open"). One can even imagine situations in which the search strategy may be changed drastically to take into account the high density of switches, and this in turn would reduce or even eliminate the delay in accessing code-switched words. Other factors that can affect access time are the context and topic of the interaction (these may sometimes lead the listener to expect many code-switches), the psychosocial characteristics of the interlocutors (some bilinguals, e.g., have negative attitudes toward code-switching and hence do not themselves code-switch or expect others to code-switch with them), and the acoustic-phonetic characteristics of the code-switches themselves. In a pilot study of English and French code-switches, we found, for example, that the acoustic-phonetic changes that occur at code-switch boundaries are spread over time. Thus, in the sentence "I saw the bac (ferry)", a spectrographic analysis showed that the /b/ of "bac" was still quite English; it was only in the following vowel that the full French acousticphonetic characteristics began to appear. This delay in acoustic-phonetic changeover probably affects the listener's identification of the code-switch's phonetic segments and hence the word's access. This phonetic factor becomes even more important in the case of codeswitches pronounced with a base-language accent or in the case of word borrowings that are integrated phonologically and morphologically into the base language; in neither instance can the listener rely on acoustic-phonetic cues to indicate the appropriate lexicon to search.

We can conclude from this discussion that the lexical access of code-switched words is a process that is both complex and variable. Inferring from our results that bilinguals always access code-switched words more slowly than base-language words would be premature and probably erroneous, for several reasons. The first is that numerous linguistic, pragmatic, and psychosocial factors can affect the access time of code-switches (as we discussed above). The second is that we did not in fact directly test the lexical access of base-language words in both speech modes; we tested these words in only the monolingual speech mode, and had to assume that their access times would be the same in a bilingual speech mode. It would be interesting to find, for example, that base-language words take more time to access in a bilingual, code-switching mode than in a monolingual mode, because the bilingual mode favors a search of the 
two lexicons, whereas the monolingual mode does not. And third, we still have no good understanding of the relationship that exists between the lexical decision task we used and the actual processing of words in realtime communication. Only the use of other paradigms, materials, and procedures will allow us to better understand how bilinguals recognize words in their different speech modes.

In the long run, a psycholinguistic model of language processing in bilinguals will have to account for the perception and production of language in the bilingual's different speech modes. It will have to describe in what ways bilinguals in the monolingual mode differ from monolinguals in terms of perception and production processes, and it will have to explain the actual interaction of the two languages during processing in the bilingual mode. The present study is an exploratory step in this direction.

\section{REFERENCES}

Altenberg, E., \& Cairns, H. (1983). The effects of phonotactic constraints on lexical processing in bilingual and monolingual subjects. Journal of Verbal Learning and Verbal Behavior, 22, 174-188.

BlaIR, D., \& Harris, R. (1981). A test of interlingual interaction in comprehension by bilinguals. Journal of Psycholinguistic Research, 10, 457-467.

Blank, M. A. (1980). Measuring lexical access during sentence processing. Perception \& Psychophysics, 28, 1-8.

BRADLEY, D. (1977). Closed class items have privileged status in the lexicon: $A$ demonstration experiment. Unpublished manuscript, Massachusetts Institute of Technology.

Caramazza, A., \& Brones, I. (1979). Lexical access in bilinguals. Bulletin of the Psychonomic Society, 13, 212-214.

Cole, R. A., \& JAkimik, J. (1979). A model of speech perception. In R. A. Cole (Ed.), Perception and production of fluent speech. Hillsdale, NJ: Erlbaum.

Diamond, N. (1982). Bilinguals in the English mode: Lexical access in bilinguals. Unpublished senior thesis, Harvard University, Department of Linguistics.

Fonsten, K. I. (1976). Accessing the mental lexicon. In R. Wales \& E. Walker (Eds.), New approaches to language mechanisms. Amsterdam: North-Holland.

Foss, D. J. (1969). Decision processes during sentence comprehension: Effects of lexical item difficulty and position upon decision time. Journal of Verbal Learning and Verbal Behavior $8,457-462$.

Foss, D. J., \& Blank, M. A. (1980). Identifying the speech codes. Cognitive Psychology, 12, 1-31.

GrosJE AN, F. (1980). Spoken word recognition processes and the gating paradigm. Perception \& Psychophysics, 28, 267-283.

Grosje AN, F. (1982). Life with two languages: An introduction to bilingualism. Cambridge, MA: Harvard University Press.

GUMPERZ, J. (1970). Verbal strategies in multilingual communication. In J. Alatis (Ed.), Bilingualism and language contact. Washington, DC: Georgetown University Press.

KIRK, R. E. (1968). Experimental design: Procedures for the behavioral sciences. Belmont, CA: Brooks/Cole.

Kolens, P. (1963). Interlingual word associations. Journal of Verbal Learning and Verbal Behavior, 2, 291-300.

Kolers, P. (1966a). Interlingual facilitation of short-term memory. Journal of Verbal Learning and Verbal Behavior, 5, 314-319.
Kolens, P. (1966b). Reading and talking bilingually. American Journal of Psychology, 3, 357-376.

Kole rS, P. (1968). Bilingualism and information processing. Scientific American, 218(3), 78-89.

Kolers, P., \& Gonzalez, E. (1980). Memory for words, synonyms, and translations. Journal of Experimental Psychology: Human Learning and Memory, 6, 53-65.

Kučera, F., \& Francis, W. (1967). Computational analysis of present-day American English. Providence, RI: Brown University.

LIPSK, J. (1978). Code-switching and the problem of bilingual competence. In M. Paradis (Ed.), Aspects of bilingualism. Columbia, SC: Hornbeam Press.

Macnamara, J. (1967). The bilingual's linguistic performance: A psychological overview. Journal of Social Issues, 23, 59-77.

Macnamara, J., \& Kushnir, S. (1971). Linguistic independence of bilinguals: The input switch. Journal of Verbal Learning and Verbal Behavior, 10, 480-487.

Marslen-Wilson, W., \& Welsh, A. (1978). Processing interactions and lexical access during word recognition in continuous speech. Cognitive Psychology, 10, 29-63.

Mehler, J., Segui, J., \& Carey, P. (1978). Tails of words: Monitoring ambiguity. Journal of Verbal Learning and Verbal Behavior, 17, 29-35.

Monton, J. (1969). Interaction of information in word recognition. Psychological Review, 76, 165-178.

Neufeld, G. (1973). The bilingual's lexical store. Working Papers on Bilingualism, 1, 35-65.

Obler, L., \& Albert, M. (1978). A monitor system for bilingual language processing. In M. Paradis (Ed.), Aspects of bilingualism. Columbia, SC: Hornbeam Press.

PANDI, G. R. (1975). Understanding bilingual messages: The concept of the language switch. Unpublished doctoral dissertation, University of California, San Francisco.

Paradis, M. (1978, December) Bilingual linguistic memory: Neurolinguistic considerations. Paper presented at the meeting of the Linguistic Society of America, Boston.

Paradis, M. (1980a). Language and thought in bilinguals. In W. G. McCormack \& H. J. Izzo (Eds.), The Sixth Lacus Forum. Columbia, SC: Hornbeam Press.

Paradis, M. (1980b). The language switch in bilinguals: Psycholinguistic and neurolinguistic perspectives. In P. Nelde (Ed.), Languages in contact and conflict. Weisbaden: Franz Steiner.

Paradis, M. (1981). Contributions of neurolinguistics to the theory of bilingualism. In R. K. Herbert (Ed.), Applications of linguistic theory in the human sciences. Michigan State University, Department of Linguistics.

Pfaff, C. (1979). Constraints on language mixing: Intrasentential code-switching and borrowing in Spanish/English. Language, 55, 291-318.

Poplack, S. (1980). "Sometimes I'll start a sentence in English Y TERMINEO EN ESPANOL": Toward a typology of codeswitching. Linguistics, 18, 581-618.

Preston, M., \& Lambert, W. (1969). Interlingual interference in a bilingual version of the Stroop Color-Word Task. Journal of Verbal Learning and Verbal Behavior. 8, 295-301.

Rubenste in, H., \& Pollack, I. (1963). Word predictability and intelligibility. Journal of Verbal Learning and Verbal Behavior, 2, 147-158.

Scotron, C., \& URY, W. (1977). Bilingual strategies: The social functions of code-switching. Linguistics, 193, 5-20.

TAYLOR, I. (1971). How are words from two languages organized in bilinguals' memory? Canadian Journal of Psychology, 25, 228-240.

Tulving, E., \& Colotla, V. (1970). Free recall of trilingual lists. Cognitive Psychology, 1, 86-98.

VAID, J. (1980). The form and function of code-mixing in Indian films: The case of Hindu and English. Indian Linguistics, 41, 37-44. 
Wakefield, JR., J. A., Bradley, P. E., Yom, B. L., \& Doughtie, E. B. (1975). Language switching and constituent structure. Language and Speech, 18, 14-19.

WOOLFORD, E. (1983). Bilingual code-switching and syntactic theory. Linguistic Inquiry, 14, 520-536.

\section{NOTE}

1. Although the bilinguals performed the same task three times (once in each language environment), whereas the monolinguals performed the task only once, we found no evidence of a practice effect in the response times. Furthermore, the percentage of correct responses to words and nonwords was $90 \%$ for bilinguals and monolinguals, and no difference was found in the answers to the comprehension questions.

(Manuscript received November 1, 1983; revision accepted for publication March 14,1984 .) 